\title{
História e cinema na escola ${ }^{1}$
}

Maria Antonieta Tourinho ${ }^{2}$

Rosane Vieira ${ }^{3}$

Resumo: Este texto relata, comenta e teoriza uma experiência na qual se buscou relacionar o cinema com o ensino de história. Essa experiência se concretizou no estágio curricular, etapa final da formação de professores, do curso de licenciatura em história da UFBA (Universidade Federal da Bahia). Os estagiários realizaram uma oficina sobre o tema no colégio Alberto Silva, localizado no município de Simões Filho. Com a intenção de fazer uma integração entre palavras e imagens, sem predomínio de umas sobre os outras, a biblioteca do colégio se transformou, todos os sábados pela manhã, em uma sala de cinema.

Palavras-chave: história, cinema, ensino de história.

Abstract: This text relates, comments and theorizes an experience which made connections between films and teaching of history. This experience has resulted in a traineeship: the final stage of teacher training of the undergraduation in history from UFBA. The trainees held a workshop on the subject at the Alberto Silva High School, located in the city of Simões Filho. Thus, the library of the school has become, every Saturday morning, in a theather, with the intention to integrate words and images, without predominance of one over the other.

Keywords: history, cinema, teaching of history. 
Como o cinema pode difundir-se pela educação básica não apenas como instrumento para o ensino e para a aprendizagem de um determinado conteúdo mas também como aproximação - intelectual, afetiva, prazerosa, instigadora - de uma das mais significativas e fascinantes invenções da modernidade?

Vimos, juntamente com meus alunos da disciplina Metodologia e prática do ensino de história, buscando essa resposta, particularmente quando discutimos sobre imagens e ensino de história, um dos temas do nosso programa. É, no entanto, nos estágios, realizados em escolas públicas de Salvador que as imagens são levadas para as salas de aula e, entre essas imagens, estão filmes que são exibidos e discutidos com alunos dos ensinos fundamental e médio. Entretanto, os conteúdos históricos acabam sempre condicionando o nosso trabalho e predominando nos caminhos percorridos nessas exibições e discussões.

A incorporação de imagens - fotos, mapas, gravuras, filmes - ao processo de ensino e aprendizagem em história tornou-se expressiva quando, em uma conversa com nossos alunos sobre o estágio curricular que eles iriam vivenciar no primeiro semestre de 2004 , vislumbramos a possibilidade de substituir o formato tradicional por uma oficina que não se limitasse à sala de aula e que acontecesse também nas ruas.

Escolhemos como tema A cidade do Salvador: cenários e histórias e, a partir disso, montamos um projeto com os alunos do colégio Odorico Tavares. Essa experiência acrescentou um diferencial significativo ao trabalho na disciplina Metodologia e prática do ensino de história, pois trouxe elementos novos às nossas discussões teórico-metodológicas - confirmando a importância das imagens no processo de ensino e aprendizagem em história. Os próprios cenários da cidade possibilitam a compreensão e a vivência da relação "passado e presente", pois, ao mesmo tempo em que estamos em um sítio histórico, as referências da atualidade interferem no processo a cada instante, funcionando como imagens vivas e animadas do conteúdo estudado. Conteúdo que foi também imaginado através de roteiros, mapas, gravuras e fotos (os quais foram 
incorporados às atividades das aulas preparatórias que antecediam cada visita a localidades históricas ocorridas durante o trabalho).

Nessa primeira oficina, apesar de o cinema não ter feito parte das nossas atividades, as imagens estiveram sempre muito presentes. Através dessa experiência, fomos percebendo que, nesse tipo de trabalho, até mesmo pelo clima de novidade que ele traz consigo, as criatividades, sobretudo no que se refere à incorporação das imagens, afetam mais intensamente o processo "ensino e aprendizagem". O aluno da educação básica, público-alvo dos estágios curriculares, se mostra mais envolvido e participativo, buscando, em alguns casos, ampliar os seus conhecimentos sobre o conteúdo estudado.

\section{Cinema na escola! Cinema com a história!}

Nesse sentido, já confiantes nas possibilidades teórico-metodológicas que um trabalho mais diversificado pode acrescentar às experiências de estágio, propusemos aos alunos do primeiro semestre de 2005 a realização de uma oficina como alternativa ao estágio tradicional - para aqueles que quisessem experimentar esse outro jeito de iniciação no universo da educação básica.

Cristiano Assis, Eliomário Borges, Ivonildo Assis, Jackson Santos Jr. e Moisés Florentino, em uma turma de 15 alunos, aceitaram tentar essa experimentação: propondo-se, assim, a utilizar o período de estágio para a realização de um minicurso em história com alunos da rede pública estadual, considerando essa escolha como uma experiência singular. A partir da formação desse grupo, começamos a pensar sobre: tema, escola, público-alvo, calendário. Uma das sugestões é que se evitassem as escolas do centro, já que queríamos realizar essa tarefa com alunos fora da "órbita" da Secretaria da Educação - até como uma forma de realizar na prática uma ação sobre a qual, infelizmente, a universidade discursa, mas não realiza: levar a universidade para a periferia. 
Dentro desses critérios, foi escolhido o colégio Alberto Silva, localizado no município de Simões Filho. Passamos a pensar na possibilidade de um curso de história para um público formado por professores e alunos que se interessassem pelo tema a ser trabalhado. Mas qual seria esse assunto? Depois de entrevermos possibilidades como passeios históricos, palestras e visitas a centros e universidades, optamos pela relação entre cinema, educação e história, intitulando essa oficina de Cinema na escola! Cinema com a história! O filme seria a chamada para os nossos estudos pedagógicos e históricos: assim, contemplados com uma escola que é bem equipada, com telão, aparelhos de DVD e de vídeo, resolvemos promover, uma vez por semana, uma sessão de cinema.

Durante dois meses, a biblioteca do colégio Alberto Silva se transformou, todos os sábados pela manhã, em uma sala de cinema, na qual foram exibidos filmes com temas referentes à história do Brasil. Assim, Caramuru: a invenção do Brasil, Brava gente brasileira; Atlântico negro: na rota dos orixás; Netto perde sua alma e $O$ que é isso companheiro? foram vistos, comentados e contextualizados por uma plateia composta por alunos e professores do colégio e pelos organizadores do evento. A intenção era, tendo o filme como chamada, tentar fazer uma integração entre palavras e imagens, sem predomínio de umas sobre as outras; buscando, dessa maneira, trilhar por um caminho tensionado, pois, como afirma Leite (1999):

O texto verbal e o visual são polissêmicos e complementares, sendo cada um mais adequado a determinadas utilizações. Portanto, embora habitualmente a linguagem visual seja considerada de transmissão direta, ela acaba tendo uma postura parasitária em relação à linguagem verbal (p. 67).

Antes e depois dessas sessões de cinema, aconteciam exposições, discussões, apresentações de textos em prosa e poesia, audição de canções e projeções de imagens referentes aos temas, já que nossa intenção era pontuar momentos significativos de nossa história, desde a ocupação pelos 
portugueses até a atualidade. Para esse passeio pela história do Brasil, foram escolhidos conteúdos substanciados com temas mais genéricos, que faziam duplas com os filmes escolhidos.

\author{
O início da oficina, no qual o filme Caramuru: a invenção do Brasil \\ fez dupla com o tema Brasil uma rota na carreira das Índias, teve a \\ coordenação de Jackson:
}

Fui o primeiro a apresentar, no dia 21/5. A sala estava relativamente cheia, com aproximadamente 30 alunos. Apresentei-me à turma e falei sobre o filme que seria apresentado: Caramuru, a invenção do Brasil, com direção de Guel Arraes e Jorge Furtado, foi realizado em 2000, tem duração de 110 minutos e tem como fio condutor a chegada acidental de Diogo Álvares de Souza "Caramuru" a essas terras e o seu casamento com "Catarina" Paraguaçu. Após a apresentação do vídeo, iniciei meu "voo panorâmico", que partiu de Portugal, nos preparativos para a viagem, até a fundação da cidade do Salvador e a montagem da sua estrutura administrativa. O filme foi escolhido por ser uma comédia que, apelando para referências zombeteiras à atualidade brasileira, trata de um tema da história do Brasil que introduz o conteúdo da oficina.

\title{
Cristiano foi o coordenador da relação entre o filme Brava gente brasileira
} e o tema O século XVIII: formação do corpo e da alma do Brasil:

Estavam programadas para o sábado, 4 de junho de 2005, a apresentação do segundo filme e sua respectiva exposição. Seguindo a apresentação de Jackson, que se deteve ao período inicial da colonização do Brasil, passamos à etapa da cristalização dessa colonização e a posterior expansão do território brasileiro. Antes da exibição, o filme foi contextualizado no mundo ocidental dos séculos XVII e XVIII: as influências das políticas mercantilistas; as disputas entre Portugal e Espanha por domínios de terras na América. O filme traz vários elementos sobre esse aspecto da formação do Brasil, particularmente sobre a natureza das expedições conhecidas como entradas e bandeiras. A representação dessas expedições, feitas por bandeirantes ou "os paulistas", fica marcante e bem apresentada. Assim, na discussão que se seguiu ao filme, aproveitando-me desse apelo imagético e documental atualizei o que considerei o eixo central do filme - os obstáculos humanos e naturais e, principalmente, o contato instável entre o branco dominador/colonizador e o índio "dominado"/usurpado -, trazendo-o para uma discussão sobre a construção da nação brasileira. Na minha apresentação, tentei traçar o processo da "formação da etnia brasileira", trazendo o conceito de miscigenação e como esta se mostra na construção do nosso país. Como 
se relacionaram as matrizes da nossa configuração étnica - o branco, o índio e o negro - nas interações sociais no percurso da história do Brasil.

A partir do documentário Atlântico negro: na rota dos orixás, Ivonildo discutiu com a plateia presente na sessão de cinema de 18 de junho de 2005 as influências africanas na cultura brasileira:

O documentário de Renato Barbieri foi o eixo de toda a apresentação. Foi a partir dele, por exemplo, que definimos o tema e selecionamos todo o material para a terceira fase do minicurso. Embora tenhamos optado pelo título As influências africanas na cultura brasileira, o filme aborda também o contrário, isto é, as influências brasileiras na cultura africana, especialmente, no Benin, pequeno país do centro-oeste africano. Fizemos esse recorte para evitar que a exposição ficasse muito longa e cansativa, já que precisávamos contextualizar, falar do tráfico, do cotidiano escravo, da resistência e traçar um paralelo com os dias atuais. Todavia, não adiantou: ela ficou longa. Não sabemos se ficou cansativa. Durante a contextualização, a turma, atenta e interessada, fez perguntas e comentários enriquecedores, tornando dialógico aquele momento de aprendizagem. Aliás, o debate, planejado para o final, ocorreu no curso da exposição. Foi até melhor, pois, assim, quebrou-se a monotonia e o monólogo.

O tema Brasil Império: processos e transformações teve como chamada o filme Netto perde sua alma, dirigido por Beto Souza e Tabajara Ruas, e essa oficina foi coordenada por Eliomário, em 7 de julho de 2005:

Seria muita pretensão conseguirmos em apenas uma manhã explicar de forma satisfatória um período com tantos acontecimentos e implicações para o nosso presente. Baseado nisso, procurei fazer um recorte dos dois maiores conflitos (Guerra do Paraguai e Guerra dos Farrapos) do Brasil Imperial. A abordagem do filme, que narra a história de um personagem real (General Netto), que participou de ambos os conflitos, foi a melhor forma de explicar o período em foco. Destaco que os próprios alunos puderam criar uma articulação com a política atual, e geraram-se pontos de vista que se confrontaram durante o debate.

Moisés coordenou dupla formada pelo filme $O$ que é isso companheiro? e pelo tema O golpe civil-militar de 1964 no Brasil: repressão e resistência armada: 
A exposição e o debate sobre repressão e resistência armada nos "anos de chumbo" da ditadura militar no Brasil, que se instaurou de 1964-1985, fizeram parte da última apresentação (14 de julho de 2005) de temas de história do Brasil e se basearam no filme $O$ que é isto companheiro?, produzido em 1997 por Bruno Barreto, que retrata nas telas de cinema a obra homônima de Fernando Gabeira. Nela, o autor discorre sobre as experiências vividas por ele e seus companheiros de luta contra a repressão do regime de exceção estabelecido em nosso país, em especial, no seu período de apogeu (1969-1974). Diferentemente de um documentário, que teria uma vantagem maior, pois é mais explicativo, o filme trabalha com a capacidade do educando de aperfeiçoar sua subjetividade e abstração. É importante ressaltar que os alunos que acompanharam as exibições e as discussões dos filmes melhoraram o seu entendimento da história, fazendo perguntas atentas e interessadas.

\section{Algumas reflexões após a oficina}

Samain, em Questões heurísticas em torno do uso das imagens nas ciências sociais (1998), propõe-se a oferecer algumas considerações relativas ao estatuto heurístico das imagens quando utilizadas pelas ciências humanas e, para se tranquilizar, atreve-se "a pensar que, em graus variados, permanecemos todos, pouco 'alfabetizados' visualmente, pouco alfabetizados, também, às práticas visuais". O autor está se referindo à pesquisa em ciências humanas, mas acreditamos que, em relação ao ensino e à aprendizagem em história, esse analfabetismo é ainda maior, visto que muitos professores desconhecem os códigos expressivos do filme, são desatentos, têm o olhar pouco apurado e, assim, estão mais propensos a conclusões precipitadas e fáceis.

Pergunta-se, então: como ensinar tais códigos aos discentes? Alfabetizar na linguagem audiovisual não é o caso, pois os alunos, assim como os professores, são espectadores habituai: dentre os produtos da cultura das mídias, o filme é cada vez mais financiado pelos grandes monopólios da comunicação, veiculado em três das grandes media - o cinema, a televisão e o computador - e divulgado em várias outras.

Conhecendo mais sobre a forma fílmica, o docente proporcionaria ao aluno um maior espaço de experiência do seu olhar, através da obra, sobre o 
mundo - que não é, precisamente, o olhar do cineasta nem das outras fontes apresentadas pelo professor, mas da fusão deles com o olhar do próprio discente, transitando pelas diferentes manifestações expressivas e permitindo que ele amplie seu conhecimento do mundo e sobre si próprio. "Um filme é como uma pessoa. É só dialogar com ele: o que podemos perguntar-lhe, o que ele pode nos responder?" (BERNARDET apud BRUZZO, 1995, p. 117).

E a fruição da beleza fílmica não é para poucos escolhidos. Esse discurso estético não tem nada de natural, já que "o imediato é, na verdade, mediado, a sensibilidade é construída; o talento pode ser formado, a inspiração adquirida, a emoção preparada" (PORCHER, 1982, p. 14). Não quer dizer, simplesmente, que todos tenham a mesma sensibilidade artística. Porém, podem tornar-se mais sensíveis à obra de arte, orientando-se livremente dentro do código artístico.

\footnotetext{
a legibilidade de uma obra de arte se define pelo grau de correspondência entre a riqueza intrínseca da mensagem e a competência artística do indivíduo, seu grau de conhecimento dos códigos e seu domínio das classificações estilísticas, o que permite a atribuição, a interpretação e o sentimento de familiaridade com a obra (FORQUIN, 1982, p. 43).
}

No entanto, o prazer estético não depende do conhecimento literal dos códigos, mas, pelo menos, do sentimento de familiaridade, proporcionado pelo contato frequente com obras de arte. Há a ditadura de um gosto estético, extremamente difundido pela cultura das mídias. Ela (de)forma o olhar do espectador porque o faz perceber depressa, superficialmente, preferindo o ilusionismo à estilização. Dessa forma, o espectador rejeita qualquer forma de abstração em prol de uma apreciação rápida, sem dificuldades. Por que não partir, então, dessa realidade artística que tanto seduz o espectador-aluno na cultura das mídias para ampliar a sua qualidade de experiência estética? Desenvolver as capacidades estético-visuais? Sem negá-la, como muitos professores, herdeiros de um elitismo artístico, fazem, ao transformar a sala de aula num cineclube de filmes de arte. 
O diálogo estético é o caminho mais curto e eficiente para ampliar e aprofundar a resposta estética: "uma vez que eu entenda como reajo àquilo de que já gosto em arte (...) posso mais prontamente explorar uma introdução das artes que não são ainda apreciadas" (LANIER, 1997, p. 54). Da mesma forma, não é interessante o professor se satisfazer com filmes de fácil fruição, que, cotidianamente, fazem parte da realidade do aluno.

Forquin (1982) ainda observa que "o desejo de expressão comanda a aprendizagem dos meios da expressão, os quais, por sua vez, alimentam e firmam esse desejo" (p. 34), ampliando a interação no mundo à medida que se educam os sentidos e a percepção. Mas é importante lembrar que esse caminho de leituras, das mais simples às mais ambiciosas, requer o interesse do aluno, que precisa fazer interagir a sua experiência de mundo com o filme.

Nesse sentido, a utilização da obra fílmica na sala de aula pode proporcionar aos sujeitos do processo "ensino e aprendizagem" a possibilidade de se afastarem de uma prática meramente mecânica e repetitiva, longe das suas vivências, ao reproduzirem símbolos e conceitos vazios de significação. Como um texto na sala de aula, esse artefato artístico estimula formas de conhecimento que escapam à linearidade da linguagem, desenvolvendo a imaginação do educando. E usar o texto fílmico é o melhor exercício para a "alfabetização imagética".

\section{Considerações finais}

Então, vamos nos "alfabetizando" no processo de ensino e aprendizagem da disciplina Metodologia e prática do ensino de história. Essa oficina foi mais um movimento em busca dessa alfabetização. A sua realização trouxe movimentação à escola e reflexões sobre o ensino de história. Os alunos do 30 ano do ensino médio que a frequentaram a consideraram, nas suas avaliações, como uma iniciativa que proporcionou: "ótima convivência, divertida, e que serviu bastante para enriquecer os nossos conhecimentos". "Os filmes 
escolhidos, os debates, a escolha dos temas que levaram a um retorno aos livros, relembrando os assuntos", a apreensão "de coisas de que só ouvia falar na escola, e livros", são outras observações que perpassam essas avaliações. Também se destacam os agradecimentos "pela atenção e carinho que tiveram com todos nós" e desejos de continuidades: "Quem sabe no próximo.... Esse foi o primeiro minicurso de história de que eu já participei e, a partir desse, eu pretendo participar de muitos outros".

Enfim, pela repercussão que teve na escola e por todo o seu desenrolar, no qual se buscou não apenas expor informações, pode-se concluir que essa oficina, muito além de apenas falar de história, foi um espaço para debates sobre cidadania, política e percepção de pessoas como agentes de suas próprias aspirações. Outro aspecto que consideramos importante foi a construção coletiva que predominou, desde o planejamento, em todo o seu processo: $E$ esse trabalho foi realmente de equipe, pois todos participavam.. Não houve disputa de conhecimento; todos agiram como verdadeiros colegas e amigos num ambiente democrático e enriquecedor.

Retomando a questão inicial, de como buscar uma complementaridade entre cinema e ensino de história, acreditamos que essa oficina foi mais um passo para a criação dessa intimidade. Entretanto não deu conta, e nem poderia dar, até porque não era essa a sua intenção, de questões conceituais como realidade, singularidades das imagens e contextualizações dos filmes no universo cinematográfico.

Buscou-se, e isso tinha um sentido, uma representação da realidade de cada período histórico estudado, mas é importante, em algum momento, se indagar: o que em cinema podemos de chamar de realidade? Leite (1999) observa:

entre a imagem e a realidade que representa, existe uma série de mediações que fazem com que, ao contrário do que se pensa habitualmente a imagem não seja restituição, mas reconstrução sempre uma alteração voluntária ou involuntária da realidade, que é preciso aprender a sentir e ver (p. 67). 
Aproveitaram-se os recursos visuais disponíveis para que a oficina transcorresse dentro de uma qualidade à qual os alunos da escola pública, de uma maneira geral, não estão acostumados. Mas ficou no ar uma dica para discussão: Cada recurso visual não tem suas próprias singularidades? Para Samain (1998), a natureza das imagens como objetos pressupõe maneiras de ver e modos de pensar, pois "ver um filme não é olhar para uma fotografia. São atos de observação, posturas de olhar muito diferentes".

Todos os filmes e os temas que foram apresentados e discutidos durante a oficina foram contextualizados historicamente e atualizados, mas fixou-se outra questão no ar: Como ampliar essa contextualização também para o mundo das imagens?

No relatório, os estagiários concluem que, "após toda essa caminhada, tanto no estágio, com a oficina, como em todo o [nosso] curso de graduação", eles podem olhar para o que fizeram e ficar gratificados com tudo o que foi feito. Nós também ficamos muito gratificadas com o desenrolar da oficina, considerando que essa experiência, e os questionamentos que suscitou, vão trazer mais elementos para as nossas discussões sobre a relação entre imagens e o ensino de história. 


\section{Referências}

BRUZZO, C. O cinema na escola: o professor, um espectador. Tese (doutorado). Campinas: Faculdade de Educação da Universidade Estadual de Campinas, 1995.

FORQUIN, J. C. "A educação artística: para quê?" In: PORCHER, L. (Org.). Educação artística: luxo ou necessidade? São Paulo: Summus, 1982.

LANIER, V. "Devolvendo arte à arte-educação". In: BARBOSA, A. M. (Org.). Arteeducação: leitura no subsolo. São Paulo: Cortez, 1997.

LEITE, M. L. M. "Texto visual e texto verbal". In: Revista Catarinense de História, Florianópolis: UFSC, v. 5, 1999.

SAMAIN, E. "Questões heurísticas em torno do uso das imagens nas ciências sociais". In: FELDMAN-BIANCO, B.; LEITE, M. (Orgs.). Desafios da imagem: fotografia, iconografia e vídeo nas ciências sociais. Campinas: Papirus, 1998.

PORCHER, L. "Aristocratas e plebeus". In: PORCHER, L. (Org.). Educação artística: luxo ou necessidade? São Paulo: Summus, 1982.

1 Esse artigo foi elaborado com base, fundamentalmente, nos relatórios de estágio de alunos. Os trechos em itálico indicam as suas falas, constantes no relatório.

2 Professora da disciplina Metodologia e prática do ensino de história, da Faced (Faculdade de Educação) da UFBA (Universidade Federal da Bahia), doutora em educação (UFBA) e pesquisadora do grupo FEP (Formação em Exercício de Professores), da Faced/UFBA.

3 Doutoranda pelo Programa de Pesquisa e Pós-Graduação em Educação, da Faculdade de Educação da UFBA, professora da Unidade de Ensino Superior de Feira de Santana e pesquisadora do Grupo FEP. 